\title{
Atividades cinegéticas direcionadas à avifauna em áreas rurais do município de Jaçanã, Rio Grande do Norte, Brasil
}

\author{
Edja Daise Oliveira Barbosa * \\ Maria das Graças Barbosa da Silva \\ Rosana Oliveira de Medeiros \\ Marcio Frazão Chaves \\ Universidade Federal de Campina Grande, Centro de Educação e Saúde \\ Sítio Olho D’água da Bica, s/nº, CEP 58750-000, Cuité - PB, Brasil \\ * Autor para correspondência \\ edjadayse@hotmail.com
}

Submetido em 30/11/2013

Aceito para publicação em 26/05/2014

\section{Resumo}

As aves constituem um dos grupos vertebrados de maior importância cinegética em todo o mundo e, no semiárido brasileiro, apresentam um importante valor econômico e cultural. Esta pesquisa visa fornecer informações sobre as espécies de aves silvestres capturadas, suas finalidades de uso e técnicas de captura no município de Jaçanã, Zona Agreste do estado do Rio Grande do Norte (Nordeste do Brasil). Os dados foram obtidos por meio de entrevistas semi-estruturadas, no período de julho de 2012 a junho de 2013 com 35 caçadores locais, selecionados através da técnica "bola de neve". A identificação avifaunística foi realizada através das técnicas checklist-entrevista e turnê-guiada. Para determinar a importância cinegética relativa das espécies, foi calculado o Valor de Uso (VU). Nesse sentido foi citado um total de 45 espécies, utilizadas para consumo alimentar (35 spp.), comercialização (22 spp.) e criação (26 spp.). Os valores de uso (VU) variaram entre 0,03 e 1,4; sendo, Columbina talpacoti a espécie registrada com maior valor de uso. Foram identificadas 14 técnicas de capturas empregadas conforme a espécie e uso a que se destinam; sendo a caça com espingarda, a caça com baladeira e a pastora, as técnicas predominantes. Foi verificado que as aves frequentemente capturadas são Passeriformes e Columbiformes. Considerando que a caça pode mudar a composição de comunidades animais e influenciar uma série de interações ecológicas, espera-se que os resultados obtidos possam servir como ferramenta para iniciativas conservacionistas no semiárido brasileiro.

Palavras-chave: Aves cinegéticas; Etnoornitologia; Semiárido; Técnicas de captura

\section{Abstract}

Hunting activities impact avifauna in rural areas of the Jaçanã municipality, Rio Grande do Norte State, Brazil. Birds are one of the largest groups of vertebrates hunted worldwide, and in the Brazilian semi-arid region bird hunting is of great economic and cultural value. We conducted a study in Jaçanã, in the Agreste Zone of Rio Grande do Norte State (Northeastern, Brazil) to provide information on the bird capture techniques used in this region, the purpose of the captures, and the species identity of hunted birds. Data were collected from July 2012 to June 2013 through semi-structured interviews with 35 local hunters, selected using a technique 
Snowball Sampling. We identified avifauna through checklist-interviews and guided tours. To determine the relative importance of each species, we calculated the value of use (VU). A total of 45 species were cited, used for food consumption (35 spp.), commercialization (22 spp.) and breeding (26 spp.). VU ranged between 0.03 and 1.4, with Columbina talpacoti having the highest value. Fourteen capture techniques were identified, employed depending on the species and their intended use; shotgun, slingshot, and herding were the predominant techniques. The most commonly captured birds belonged to Passeriformes and Columbiformes. Hunting can alter animal community composition and may influence a multitude of ecological interactions, hence the results obtained here may serve as a valuable tool for conservation initiatives in the Brazilian semi-arid region.

Key words: Capture techniques; Ethno-ornithology; Game birds; Semi-arid

\section{Introdução}

A variedade de interrelações que as populações humanas mantêm com os animais data de períodos préhistóricos e vêm se perpetuando ao longo dos tempos. Como consequência, essa ligação direta com o meio permitiu ao ser humano uma maior capacidade de adaptação a diferentes ambientes e condições, gerando relações de dependência e co-dependência dos recursos naturais, incluindo a fauna (ALVARD et al., 1997; ALVES et al., 2009; ALVES; SOUTO, 2010).

Dentre as muitas atividades realizadas pelo ser humano na busca pela sobrevivência, a caça destacase como uma das atividades mais antigas que se tem conhecimento, e tem sido apontada como um dos principais fatores ligados à redução populacional da fauna silvestre brasileira (RENCTAS, 2001; SILVEIRA; STRAUBE, 2008; ALVES; SOUTO, 2010; IUCN, 2013; BIRDLIFE INTERNATIONAL, 2014).

As aves têm demonstrado ser um dos grupos animais que mais desperta interesse nos humanos, agregando grande importância ecológica, cultural, psíquica e utilitária. Em geral elas destacam-se entre os grupos vertebrados com maior diversidade, com representantes em quase todos os níveis tróficos, por serem espécies facilmente identificáveis (em sua maioria com atividades diurnas) e por existirem métodos bem desenvolvidos para o seu estudo, podendo ainda ser utilizadas como indicadores da qualidade ambiental de determinadas áreas. Além de ser considerado um dos grupos animais de maior importância cinegética em todo o mundo (SICK, 2001; FERREIRA; GLOCK, 2004; ROCHA et al., 2006; SAIKI, 2008; NOBREGA et al., 2011; BEZERRA et al., 2012b).
Para uma melhor compreensão das interrelações existentes entre as populações humanas e as aves, a ciência etnoornitológica mostra-se uma linha de pesquisa valiosa (CADIMA; MARÇAL-JÚNIOR, 2004; SOUZA; SOARES-FILHO, 2005; ALMEIDA et al., 2006; FARIAS; ALVES, 2007a; 2007b; SANTOS; COSTA-NETO, 2007; GAMA; SASSI, 2008; BARBOSA et al., 2009; 2010; NOBREGA et al., 2011; MENDONÇA et al., 2012; ALVES et al., 2013a; LICARIÃO et al., 2013). Por outro lado, mesmo a avifauna brasileira sendo conhecida e admirada em todo o mundo, a etnoornitologia ainda é pouco explorada no Brasil (FARIAS; ALVES, 2007b; SAIKI, 2008), o que, para Saiki (2008), representa uma contradição à boa documentação científica existente sobre este grupo.

Em se tratando dos domínios morfoclimáticos da caatinga, a comercialização, a criação e o abate de aves são práticas tradicionais, apreciadas e mantidas pelas populações urbanas e rurais, promovendo muitas vezes, sérias consequências ambientais (LEAL et al., 2005; PEREIRA; BRITO, 2005; ROCHA et al., 2006; GAMA; SASSI, 2008; NOBREGA, 2009; BARBOSA et al., 2010; FERNANDES-FERREIRA et al., 2010; BEZERRA et al., 2011a; 2012a). Nesta região, a utilização exacerbada da fauna tem representado um dos maiores desafios para a ciência brasileira em nível de conservação de espécies, num momento em que muitas áreas ainda carecem de estudos mais detalhados sobre a riqueza e utilização de espécies (SILVA et al., 2003). Vale também ressaltar que, nestas áreas, constata-se que grande parte da população vive de forma precária, principalmente as populações rurais que passam por longos períodos de seca afetando assim suas atividades de subsistência, como a agricultura e a criação de animais. 
De modo particular, o estado do Rio Grande do Norte é considerado um dos domínios brasileiros que mais apresentam escassez de dados sobre a biodiversidade. No caso específico da ornitologia, embora algumas localidades estejam sendo paulatinamente amostradas, a maior parte do estado permanece inexplorada (VARELA-FREIRE; ARAÚJO, 1997; PEREIRA, 2010; DA SILVA et al., 2012; BEZERRA et al., 2013). Adicionalmente, cabe destacar que pesquisas com enfoque etnoornitológico no semiárido potiguar são incipientes, em se tratado de dados relativos à caça até o momento, poucos estudos foram realizados (BEZERRA et al., 2011a; 2011b; 2012a).

Considerando-se a carência de estudos que retratem o uso dos recursos avifaunísticos no semiárido potiguar; a presente pesquisa visa: (1) Apresentar dados sobre aspectos das atividades de caça direcionada a avifauna no município de Jaçanã - Rio Grande do Norte. (2)
Listar as espécies de aves silvestres capturadas na localidade e suas categorias de uso. (3) Identificar, dentre as pesquisadas, quais são as espécies comercializadas e as mais procuradas. (4) Descrever as técnicas de caça utilizadas pelos caçadores locais. (5) Verificar a percepção dos caçadores sobre o status da conservação da avifauna local.

\section{Material e Métodos}

\section{Área de estudo}

A pesquisa foi desenvolvida na zona rural do município de Jaçanã $\left(06^{\circ} 25^{\prime} 33^{\prime \prime} \mathrm{S} ; 36^{\circ} 12^{\prime} 18^{\prime \prime} \mathrm{W}\right)$, área inserida na Microrregião da Borborema Potiguar, Zona Agreste do estado do Rio Grande do Norte - Nordeste, Brasil (Figura 1). De acordo com o IBGE (2010), a

FIGURA 1: Localização da área de estudo (Jaçanã - Rio Grande do Norte, Brasil).

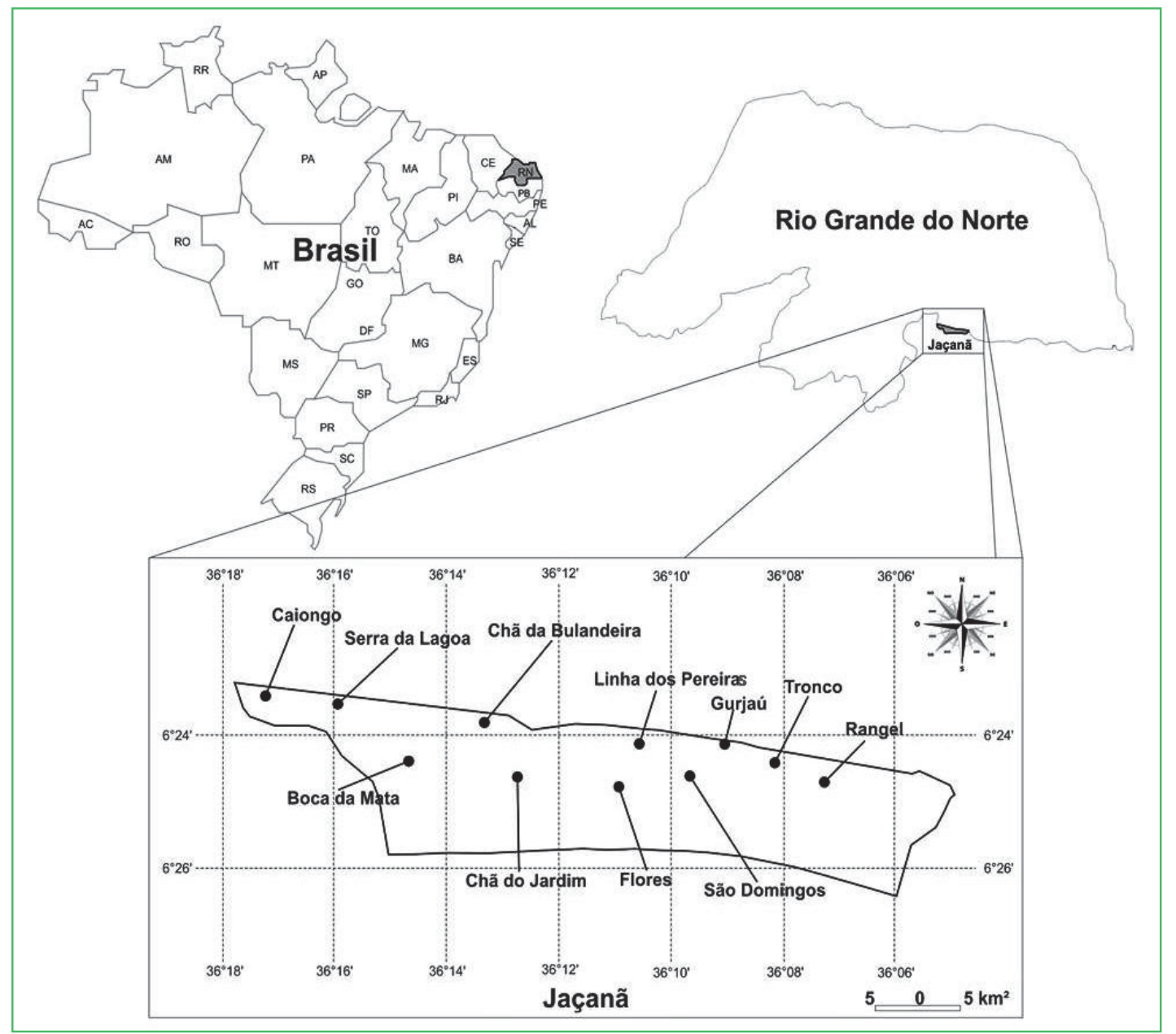


população estimada do município é de 7.925 habitantes, dos quais são 5.333 residentes na zona urbana e 2.595 residentes na zona rural. Sua área de extensão territorial é de $58,4 \mathrm{~km}^{2}$, equivalente a $0,11 \%$ do território estadual, com altitude de $664 \mathrm{~m}$ acima do nível do mar (na sede), sendo considerada uma das cidades mais altas do estado. A região é caracterizada por uma vegetação tipicamente formada pela Caatinga Hipoxerófila e o clima é predominantemente semiárido, seco e frio, com temperatura variando entre $15^{\circ} \mathrm{C}$ e $29^{\circ} \mathrm{C}$. Para o estudo foram definidas como áreas de amostragem 11 (onze) localidades rurais (sítios) do município, quais sejam: Flores, Serra da Lagoa, Caiongo, Boca da Mata, Linha dos Pereiras, São Domingos, Rangel, Chã do Jardim, Tronco, Chã da Bulandeira e Gurjaú. As principais atividades econômicas desenvolvidas no município são: agricultura de subsistência, pecuária e comércio (MARIO, 2003; IDEMA, 2008).

\section{Coleta de dados}

O estudo foi realizado em áreas rurais do município de Jaçanã-RN, no período de julho de 2012 a junho de 2013. No primeiro mês de coleta de dados foram realizadas visitas iniciais de aproximação com as áreas rurais a serem estudadas e seus possíveis informantes. Posteriormente foram realizadas conversas informais e entrevistas semi-estruturadas (AMOROZO; VIERTLER, 2010; ALBUQUERQUE et al., 2010) com caçadores de cada comunidade rural. Os informantes foram selecionados através da técnica de amostragem "bola de neve" (BAILEY, 1982). Antes de cada entrevista foi explicado a natureza e os objetivos da pesquisa, e solicitado a cada informante a permissão para o registro das informações. Aos que concordaram em participar, foi entregue o Termo de Consentimento Livre e Esclarecido (TCLE), ficando uma via com o pesquisador e a outra com o informante. As entrevistas duravam entre $40 \mathrm{e}$ 80 minutos e ocorriam nas residências dos informantes em horários variados, geralmente no período da tarde, entre as $14 \mathrm{~h} 00 \mathrm{~min}$ e $17 \mathrm{~h} 00 \mathrm{~min}$, ou de acordo com a disponibilidade dos mesmos.

A identificação avifaunística foi realizada através da técnica checklist-entrevista, com a utilização de estímulos visuais (foto-identificação) e visualização direta. A visualização direta das espécies in situ foi realizada através da técnica turnê-guiada, percorrendo-se as áreas de estudos, e sempre que possível realizavase registros fotográficos (SPRADLEY; MCCURDY, 1972; ALBUQUERQUE et al., 2010; MEDEIROS et al., 2010). As informações coletadas foram analisadas qualitativamente, segundo o modelo de união das diversas competências individuais (HAYS, 1976). O ordenamento taxonômico segue as determinações do Comitê Brasileiro de Registros Ornitológicos (CBRO, 2011).

Para determinar a importância cinegética relativa das espécies citadas, foi calculado o Valor de Uso (VU) de cada uma delas seguindo a proposta apresentada por Phillips et al. (1994), através da seguinte fórmula: $\mathrm{VU}=\Sigma \mathrm{U} / \mathrm{n}$; onde: $\mathrm{VU}=$ valor de uso da espécie; $U$ = número de citações por espécie; $\mathrm{n}=$ número de informantes.

A projeto de pesquisa foi aprovado pelo Comitê de Ética do Hospital Universitário Alcides Carneiro Universidade Federal de Campina Grande (protocolo/ CEP n ${ }^{\circ}$ 610.620).

\section{Caracterização da amostra}

Para a sistematização da pesquisa foram contatados 43 moradores rurais das localidades amostradas, destes, 35 aceitaram participar da pesquisa, sendo todos do sexo masculino e praticantes de atividades de caça e a grande maioria nativa do local $(72 \%)$. Os informantes apresentaram idades variando entre 20 e 81 anos. O nível de escolaridade da população amostrada é majoritariamente baixo, ao passo que $(9 \%)$ dos respondentes possui o ensino médio, (14\%) ensino fundamental completo e, a maioria (40\%), declarara possuir apenas o ensino fundamental incompleto ou se intitularam analfabetos (37\%). O tempo de residência na área de estudo variou entre menos de 10 a mais de 80 anos e as ocupações profissionais distribuíram-se em: pedreiro, estudante e agricultor, sendo que a maior parte dos respondentes se intitulou agricultor (88\%). 


\section{Resultados e Discussão}

\section{Atividades cinegéticas}

As entrevistas nos revelaram que a caça de aves é uma atividade característica da localidade estudada. Segundo os informantes da pesquisa, esta prática geralmente tem início na infância, estendendo-se até a fase adulta. Na infância, esta é realizada com o auxílio de "baladeira" (estilingue) e praticada como lazer. Já entre os adultos, mostrou-se, na maioria das vezes, efetuada para ser utilizada como complemento alimentar. Poucos foram os caçadores que relataram capturar aves para fins comerciais, ou como entretenimento.

Foi citado um total de 45 espécies de aves capturadas no município de Jaçanã, distribuídas em 22 famílias e 37 gêneros (Tabela 1). As famílias mais representativas quanto ao numero de espécies foram Emberizidae (sete spp.) e Columbidae (sete spp.). Seguindo padrões apresentados para o semiárido brasileiro (BARBOSA et al., 2010; ALVES et al., 2010a; 2012).

TABELA 1: Identificação das espécies de aves silvestres citadas como alvo de caça no município de Jaçanã (Rio Grande do Norte, Brasil), com seus respectivos números de citações por categorias de uso e valores de uso (VU).

\begin{tabular}{|c|c|c|c|c|c|}
\hline \multirow{2}{*}{ Identificação taxonômica } & \multirow{2}{*}{$\begin{array}{c}\text { Nome } \\
\text { popular }\end{array}$} & \multicolumn{3}{|c|}{ Citações por categorias de uso } & \multirow[t]{2}{*}{ VU } \\
\hline & & Criação & Consumo & Comércio & \\
\hline \multicolumn{6}{|l|}{ TINAMIFORMES Huxley, 1872} \\
\hline \multicolumn{6}{|l|}{ Tinamidae Gray, 1840} \\
\hline Crypturellus tataupa (Temminck, 1815) & Lambú espanta- boiada & - & 11 & - & 0,31 \\
\hline Crypturellus parvirostris (Wagler, 1827) & Lambú & - & 27 & 4 & 0,88 \\
\hline \multicolumn{6}{|l|}{ Accipitriformes Bonaparte, 1831} \\
\hline \multicolumn{6}{|l|}{ Accipitridae (Vigors, 1824) } \\
\hline Elanus leucurus (Vieillot, 1818) & Gavião & - & 3 & - & 0,09 \\
\hline \multicolumn{6}{|l|}{ Ralidae Rafinesque, 1815} \\
\hline Gallinula galeata (Lichtenstein, 1818) & Galinha d'água & - & 1 & - & 0,03 \\
\hline \multicolumn{6}{|l|}{ COLUMBIFORMES Latham, 1790} \\
\hline \multicolumn{6}{|l|}{ Columbidae Leach, 1820} \\
\hline Columbina talpacoti (Temminck, 1811) & Rolinha-cambuta & 8 & 24 & 6 & 1,08 \\
\hline Columbina minuta (Linnaeus, 1766) & Rolinha-cabocla & 8 & 35 & 6 & 1,4 \\
\hline Columbina picui (Temminck, 1813) & Rolinha-branca & 4 & 12 & 3 & 0,54 \\
\hline Leptotila verreauxi (Bonaparte, 1855) & Juriti & 9 & 2 & - & 0,31 \\
\hline Zenaida auriculata (Des Murs, 1847) & Arribaçã & - & 29 & 5 & 0,97 \\
\hline Patagioenas picazuro (Temminck, 1813) & Asa-branca & 6 & 1 & 2 & 0,26 \\
\hline \multicolumn{6}{|l|}{ PSITTACIFORMES Wagler, 1830} \\
\hline \multicolumn{6}{|l|}{ Pisittacidae Rafinesque, 1815} \\
\hline Forpus xanthopterygius (Spix, 1824) & Periquito & 9 & 2 & 4 & 0,43 \\
\hline Primolius maracanã (Vieillot, 1816) & Maracanã & 5 & - & 4 & 0,26 \\
\hline \multicolumn{6}{|l|}{ Cuculiformes Wagler, 1830} \\
\hline \multicolumn{6}{|l|}{ Cuculidae Leach, 1820} \\
\hline Coccyzus melacoryphus (Vieillot, 1817) & Papa-largata & - & 1 & - & 0,03 \\
\hline \multicolumn{6}{|l|}{ Strigiformes Wagler, 1830} \\
\hline \multicolumn{6}{|l|}{ Strigidae Leach, 1820} \\
\hline Glaucidium brasilianum (Gmelin, 1788) & Caboré & - & 2 & - & 0,06 \\
\hline \multicolumn{6}{|l|}{ Caprimulgiformes Ridgway, 1881} \\
\hline \multicolumn{6}{|l|}{ Caprimulgidae (Vigors, 1825) } \\
\hline Nyctiphrynus ocellatus (Tschudi, 1844) & Bacurau & 2 & 2 & - & 0,12 \\
\hline
\end{tabular}


Galbuliformes Fürbringer, 1888

Bucconidae Horsfield, 1821

Nystalus maculatus (Gmelin, 1788)

Fura-barreira

0,03

PASSERIFORMES Linnaeus, 1758

Thamnophilidae (Swainson, 1824)

Taraba major (Vieillot, 1816)

Myrmorchilus strigilatus (Wied, 1831)

Furnariidae Gray, 1840

Furnarius leucopus (Swainson, 1838)

Synallaxis frontalis (Pelzeln, 1859)

Tyrannidae Vigors, 1825

Tyrannus melancholicus (Vieillot, 1819)

Empidonomus varius (Vieillot, 1818)

Corvidae Leach, 1820

Cyanocorax cyanopogon (Wied, 1821)

Troglodytidae (Swainson, 1831)

Troglodytes musculus (Naumann, 1823)

Turdidae Rafinesque, 1815

Turdus rufiventris (Vieillot, 1818),

Mimidae Bonaparte, 1853

Mimus saturninus (Lichtenstein, 1823)

Coerebidae d'Orbigny \& Lafresnaye, 1838

Coereba flaveola (Linnaeus, 1758)

Thraupidae Cabanis, 1847

Tangara cayana (Linnaeus, 1766)

Tangara sayaca (Linnaeus, 1766)

Paroaria dominicana (Linnaeus, 1758)

Lanio pileatus (Wied, 1821)

Emberizidae Vigors, 1825

Sicalis flaveola (Linnaeus, 1766)

Sporophila lineola (Linnaeus, 1758)

Sporophila nigricollis (Vieillot, 1823)

Sporophila albogularis (Spix, 1825)

Zonotrichia capensis (Statius M., 1776)

Volatinia jacarina (Linnaeus, 1766)

Sporophila bouvreuil (Statius M., 1776)

Cardinalidae (Ridgway, 1901)

Cyanoloxia brissonii (Lichtenstein, 1823)

Icteridae Vigors, 1825

Icterus jamacaii (Gmelin, 1788)

Icterus cayanensis (Vigors, 1825)

Gnorimopsar chopi (Vieillot, 1819)

Molothrus bonariensis (Gmelin, 1789)

Fringilidae Leach, 1820

Sporagra yarrellii* (Audubon, 1839)

Euphonia chlorotica (Linnaeus, 1766)

* Espécie ameaçada de extinção.

\begin{tabular}{|c|c|c|c|c|}
\hline Choró & - & 3 & - & 0,09 \\
\hline Piu-piu & - & 1 & - & 0,03 \\
\hline João-de-barro & 1 & 1 & - & 0,06 \\
\hline Tio-antônio & - & 1 & - & 0,03 \\
\hline Bem-ti-vi & - & 3 & - & 0,09 \\
\hline Peitica & - & 2 & - & 0,06 \\
\hline Cancão & 2 & - & 1 & 0,08 \\
\hline Rouxinol & - & 1 & 1 & 0,06 \\
\hline Sábia-laranjeira & 5 & 1 & 5 & 0,31 \\
\hline Papa-sebo & - & 3 & - & 0,09 \\
\hline Chupa-mel & 2 & 1 & - & 0,09 \\
\hline Sanhaçu-pega & 2 & 3 & - & 0,14 \\
\hline Sanhaçu-azul & 4 & 2 & - & 0,17 \\
\hline Galo-de-campina & 19 & 1 & 5 & 0,63 \\
\hline Maria-fita & 2 & 2 & - & 0,12 \\
\hline Canário-da-terra & 6 & - & 7 & 0,37 \\
\hline Bigode & 2 & - & 7 & 0,14 \\
\hline Papa-capim & 7 & - & 2 & 0,26 \\
\hline Golinha & 13 & 5 & 8 & 0,74 \\
\hline Tico-tico & - & 3 & 1 & 0,12 \\
\hline Tiziu & - & 1 & - & 0,03 \\
\hline Caboclolinho & - & - & 6 & 0,17 \\
\hline Azulão & 12 & - & 8 & 0,57 \\
\hline Concriz & 11 & - & 2 & 0,37 \\
\hline Pêga & 6 & - & 3 & 0,26 \\
\hline Craúna & 3 & 4 & - & 0,2 \\
\hline Anumará & 1 & 1 & - & 0,06 \\
\hline Pintassilva & 5 & - & 4 & 0,26 \\
\hline Vêm-Vêm & - & 1 & - & 0,03 \\
\hline
\end{tabular}


Dentre as espécies listadas: cancão (Cyanocorax cyanopogon), arribaçã (Zenaida auriculata), galode-campina (Paroaria dominicana - Figura 2F) e concriz (Icterus jamacaii - Figura 2D) destacam-se como espécies endêmicas da caatinga (SICK, 2001). E o pintassilva (Sporagra yarrellii) apresenta situação mais delicada dentre as espécies listadas. Além de estar documentado na Lista Nacional das Espécies da Fauna Brasileira Ameaçada de Extinção (SILVEIRA; STRAUBE, 2008), é considerado como globalmente vulnerável (IUCN, 2013).
A pesquisa apontou que grande parte das aves capturadas enquadra-se em mais de uma categoria de uso. O canário-da-terra (S. flaveola - Figura $2 \mathrm{H}$ ) e o galo-decampina (P. dominicana - Figura 2F), por exemplo, além de serem pássaros de estimação e bastante comercializados, foram indicados por estarem relacionadas a uma prática esportiva ilegal comum no nordeste brasileiro, as "rinhas", ou seja, brigas entre pássaros (ALVES et al., 2010a; FERNANDES-FERREIRA et al., 2012). O S. flaveola é o principal pássaro relacionado a esta prática em diferentes regiões do Brasil (SICK, 2001; GAMA; SASSI, 2008;

FIGURA 2: Fotografias de algumas espécies de aves utilizadas como animais de estimação no município de Jaçanã (Rio Grande do Norte, Brasil). (A) Golinha - Sporophila albogularis; (B) Asa-branca - Patagioenas picazuro; (C) Craúna - Gnorimopsar chopi; (D) Concriz - Icterus jamacaii; (E) Azulão - Cyanoloxia brissonii; (F) Galo-de-campina - Paroaria dominicana; (G) Papagaio - Amazona aestiva; (H) Canário-da-terra - Sicalis flaveola; (I) Chupa-mel - Coereba flaveola; (J) Pêga - Icterus cayanensis; (L) Filhote de Asa-branca - Patagioenas picazuro; (M) Tico-tico - Zonotrichia capensis.
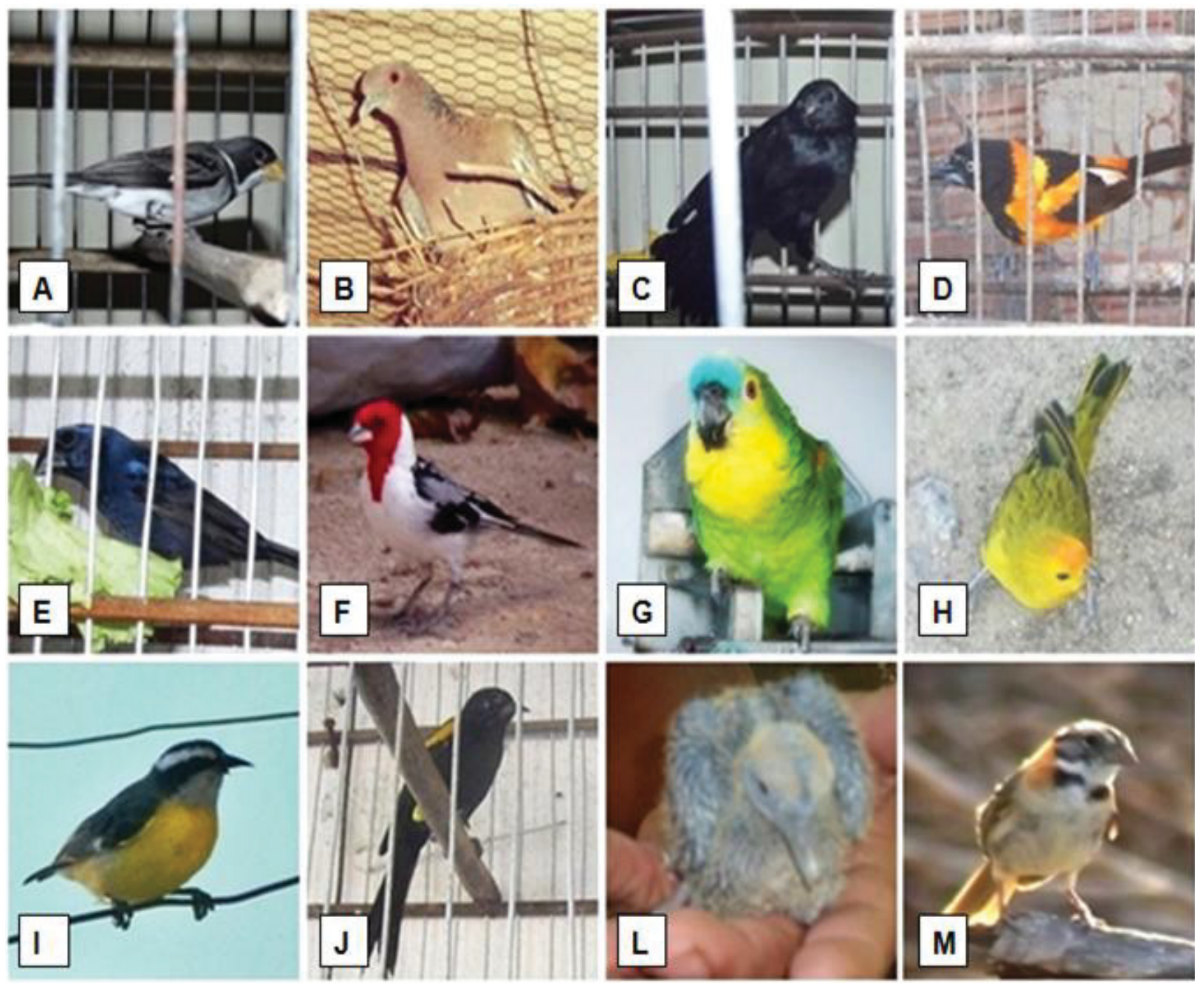

Fotos: Edja Daise (2012/2013). 
PAGANO et al., 2010; FERNANDES-FERREIRA et al., 2012). Além disso, foi relatada a comercialização de um exemplar desta espécie por $\mathrm{R} \$ 500,00$ reais e que o valor da espécie é proporcional à qualidade do pássaro em ser "bom de briga".

\section{Categorias de uso da avifauna}

Foram três as categorias de uso descritas para as espécies capturadas: Consumo Alimentar, Comercialização e Criação e os valores de uso (VU) variaram entre 0,03 e 1,4 (Tabela 1).

\section{Consumo alimentar}

Uma parcela significativa dos caçadores entrevistados (69\%) afirmou praticar a caça de aves silvestres apenas para consumo, como forma complementar a dieta. Diversos estudos indicam que a carne de caça representa uma importante via de obtenção de proteína animal para comunidades rurais do nordeste brasileiro (BARBOSA et al., 2009a; 2009b; NOBREGA et al., 2011; ALVES et al., 2010b; 2012).

Esta finalidade de uso representou a maior parte das aves exploradas (77\%), sendo Columbidae a família mais representativa quanto ao número de espécies. Considerando a importância alimentar desta família, constatação similar foi descrita no semiárido paraibano (ALVES et al., 2009; NOBREGA et al., 2011), no estado do Ceará (FERNANDES-FERREIRA et al., 2012) e em diferentes áreas do semiárido potiguar (BEZERRA et al., 2011a). Isto nos permite supor que há uma predominância na escolha das espécies de aves utilizadas para fins alimentícios em diferentes regiões semiáridas. A rolinha-cabloca (Columbina minuta) foi à espécie registrada com maior valor de uso neste estudo $(\mathrm{VU}=1,4$ - Tabela 1$)$, sendo o conhecimento acerca de sua utilização, particularmente para o consumo alimentar, distribuído de maneira uniforme entre os caçadores locais.

São muitas as dificuldades enfrentadas pelas populações humanas do nordeste brasileiro. De modo geral, a carência de recursos, atrelado às condições adversas e inerentes de ambientes semiáridos e a falta de assistencialismo por parte do governo, contribuem significativamente para a utilização da fauna silvestre por estas populações, não havendo interrupção do uso durante todo o ano. Além disso, um dos desafios mais evidentes para estes povos é sem dúvida nenhuma o fenômeno das secas. Historicamente os sertanejos têm se confrontado com a irregularidade da chuva em suas atividades produtivas, provocando diversos prejuízos de safra e pecuária, induzindo-os a buscar outros meios para satisfazer suas necessidades (PEREIRA; BARACUHY, 2011).

\section{Criação em cativeiro}

A criação de aves silvestres em cativeiro é um hábito arraigado na população brasileira (SICK, 2001) e na região estudada não é diferente. O presente estudo aponta como sendo recorrente o uso desse grupo como animais de estimação, sendo criados em gaiolas e/ou em viveiros. De acordo com Ribeiro e Silva (2007), as aves eram criadas em cativeiro mesmo antes da colonização, podendo este ser considerado um dos fatores que contribuem para o declínio populacional de muitas espécies (COLLAR et al., 1997; ALVES et al., 2010a).

Foi indicado um total 26 espécies de aves selvagens capturadas para a manutenção em cativeiro (como amimais de estimação), sendo galo-de-campina (P. dominicana - Figura 2F), golinha (Sporophila albogularis - Figura 2A) e azulão (Cyanoloxia brissonii-Figura 2E) as espécies mais citadas. A ordem Passeriformes representou $69 \%$ do total de espécies relacionadas a esta categoria. Representantes desta ordem destacam-se entre as espécies mais apreciadas em diferentes regiões (FERREIRA; GLOCK, 2004; PEREIRA; BRITO, 2005; ROCHA et al., 2006; GAMA; SASSI, 2008; BEZERRA et al., 2012b; LICARIÃO et al., 2013) e consequentemente apresentam elevados índices de captura na natureza. Evidenciando o interesse generalizado da população brasileira por aves canoras (SICK, 2001).

Observou-se que alguns moradores criam aves que permanecem em suas casas durante anos e algumas são adquiridas ainda filhotes. A captura de filhotes gera um vínculo afetivo entre o criador e a ave, que provavelmente, deve-se ao processo imprinting que 
significa o comportamento de reconhecimento e aprendizagem do jovem de uma espécie identificando seus pais após sua eclosão. Comportamento este, comumente observado em aves, podendo ocorrer em outros grupos animais (CARDOSO; SABBATINI, 2001; BEZERRA et al., 2012b). Mesmo não sendo alvo de caça in situ no município de Jaçanã, foi observado também a criação de papagaios (Amazona aestiva Figura 2G) e de aves exóticas, das quais, podemos citar: pombo (Columba livia), rolinha-burguesa (Streptopelia decaocto) e canário-belga (Serinus canaria).

\section{Comercialização}

No Brasil, a caça e o comércio predatório da fauna silvestre são práticas antigas, que passaram a ser ilegais no ano de 1967, pois até então não havia legislação que proibisse essas atividades (RENCTAS, 2001). Estudos realizados no país indicam que as aves representam o grupo animal mais comercializado e sua comercialização é nacionalmente generalizada (RENCTA, 2001; SICK, 2001; RIBEIRO; SILVA, 2007; ALVES et al., 2010a; 2013b; REGUEIRA; BERNARD, 2012).

Regueira e Bernard (2012) em um estudo realizado no Recife constataram que, apenas oito feiras-livres analisadas na região metropolitana do estado podem ser responsáveis pela comercialização ilegal de cerca de 50 mil aves silvestres anualmente, atividade altamente rentável, movimentando até $630.000,00$ dólares por ano.

Alves et al. (2013b) discorrem que, sem dados detalhados sobre as espécies comercializadas e a quantidade manipulada é impossível avaliar com precisão o impacto deste comércio sobre a avifauna selvagem. Neste sentido, tais autores catalogaram as espécies de aves vivas envolvidas em negociações no Brasil e constataram que pelo menos 295 espécies de aves são comercializadas como animais de estimação no país. No entanto, é valido citar que este número está longe de ser abrangente, uma vez que, dados científicos abordando a temática são limitados a poucas localidades brasileiras.

Nesta pesquisa, foi identificado um total de 22 espécies de aves comercializadas e sua comercialização envolve espécies vivas e abatidas. Os exemplares comercializados vivos são utilizados como animais de estimação, já os abatidos são geralmente vendidos como iguaria em bares da região. Geralmente os comerciantes têm a caça comercial como uma fonte de renda complementar, mantendo as espécies em suas residências até o momento da venda.

A partir dos resultados obtidos, observou-se uma preferência comercial pelos pássaros pertencentes à família Emberizidae, por se tratar de uma família com elevada diversidade, pelas suas habilidades de canto, além de serem espécies exploradas para diversas finalidades, corroborando com o observado por Pereira e Brito (2005), Souza e Soares-Filho (2005), Rocha et al. (2006), Gama e Sassi (2008), Fernandes-Ferreira et al. (2010), Gogliath et al. (2010) e Pagano et al. (2010), Alves et al. (2013a).

Dentre as espécies comercializadas, as de maior procura e consequentemente mais valorizadas são: o azulão (C. brissonii - Figura 2E), o golinha ( $S$. albogularis - Figura 2A), o canário-da-terra $(S$. flaveola - Figura 2H) e o bigode (Sporophila lineola), vendidos por preços que variam entre $\mathrm{R} \$ 5,00$ e $\mathrm{R} \$$ 500,00 reais.

Em suma, foi verificado que as aves mais frequentemente comercializadas são Passeriformes. Essas espécies estão entre as mais populares e mantidas em cativeiro pelos criadores em diversas regiões do Brasil (SILVEIRA; MÉNDEZ, 1999; FERNANDESFERREIRA et al., 2010; 2012; PAGANO et al., 2010; BEZERRA et al., 2012b; PREUSS; SCHAEDLER, 2012), despertando grande interesse devido suas belezas e habilidades de canto, ou no caso do canárioda-terra (S. flaveola - Figura 2H) por ser considerado "bom de briga". Ademais, há sempre preferência pelos exemplares machos, conforme observado por Ribeiro e Silva (2007), por possuírem uma maior capacidade de canto e plumagem mais bonita.

\section{Técnicas de caça}

A caça é uma prática que vem sendo desempenhada pelo ser humano desde a antiguidade, e sendo assim, desde então diversas técnicas foram e são desenvolvidas para auxiliar na captura e/ou abate das espécies 
desejadas, adotadas conforme a espécie e a finalidade a que se destina o animal capturado (ALVES et al., 2010b).

Foi identificado o uso de 14 técnicas tradicionais de captura de aves no município de Jaçanã e como descrito por Lee (2000), estas podem ser ativas, ou seja, com a presença do caçador na hora da captura, ou passivas, com o auxílio de armadilhas. Sendo elas: caça com espingarda (Figura 3M), caça com "baladeira" (estilingue - Figura 3I), "pastora", "gaiola de campo", "assaprão" (Figura 3G), "redinha" (Figura - 3H), "arapuca" (Figura 3J), "quixó" (Figura 3L), "visgo", "bozó", "fôjo" (Figura 3E), "arremedo" (Apitos, Figura-3A, B, C), "facheada" e a "técnica manual". Para tanto, a caça com espingarda (54\%), a caça com "baladeira" (34\%), e a "pastora" $(31 \%)$ foram às técnicas predominantes.

A caça com espingarda (arma de fogo - Figura 3M) e a caça com "baladeira" (Figura 3I) são técnicas ativas, amplamente difundidas em território brasileiro e estão diretamente relacionadas ao abate (BARBOSA et al., 2009; ALVES et al., 2012; BEZERRA et al., 2012b; FERNANDES-FERREIRA et al., 2012). A "baladeira" (Figura 3F), também chamada de estilingue, é um objeto construído com forquilha de madeira, borracha de soro e couro, utilizado com pedras para serem arremessadas na direção da ave. Em ambas as técnicas, o caçador fica na espreita até as aves aparecerem.

A "pastora" ou "espera" é uma estratégia de caça ativa diurna, na qual os caçadores ficam camuflados entre as plantas portando espingardas e/ou "baladeiras" até as aves aparecerem. Adicionalmente, essa técnica também é realizada com a construção de uma estrutura em forma de "esconderijo", confeccionada com galhos de plantas locais em um local frequentemente visitado por diversas aves, geralmente próximo a lagoas ou a ambientes que os animais costumam visitar para se alimentarem. Uma vez construída a estrutura, os caçadores ficam à espreita em seu interior, aguardando as presas para o abate. Semelhanças no uso desta técnica foram relatadas por Alves et al. (2010b) no semiárido paraibano. Além disso, os caçadores afirmam usar roupas semelhantes a do exército para auxiliar na camuflagem.

A gaiola de campo consiste em uma gaiola de madeira com espaçamentos de arames maiores. Essa armadilha é exclusivamente empregada para a captura de azulões (Cyanoloxia brissonii - Figura 2E). Nessa técnica, utiliza-se sempre um exemplar C. brissonii (treinado) para auxiliar na captura de outros desta espécie, de modo que, o pássaro selvagem é atraído pelo que está dentro da gaiola, que por sua vez, utiliza o seu bico para capturar o pássaro que está do lado de fora da gaiola, segurando-o até o caçador pegá-lo.

O "assaprão" (Figura 3G) consiste em uma gaiola pequena eventualmente utilizada para capturar exemplares vivos, geralmente Passeriformes. Nesta armadilha, a abertura superior da gaiola permanece suspensa em um sistema de desarme. Ao pousar no interior da armadilha, o pássaro acaba ficando preso. Em geral é armada em locais estratégicos com algum tipo de isca para atrair a ave, geralmente utiliza-se alpiste (gramínea). Adicionalmente foi verificado que o "assaprão" pode ser ainda agregado à outra gaiola e levado a campo com algum pássaro cantador, popularmente conhecido como "chama", termo usado para o pássaro eventualmente utilizado para atrair outros pássaros. Conforme descrito em outros estudos (FERNANDES-FERREIRA et al., 2010; 2012), os "chamas" podem ser fêmeas ou machos que acabam atraindo outros exemplares, geralmente da mesma espécie.

A "arapuca" (Figura 3J) consiste em uma armadilha confeccionada com gravetos de madeira, empilhada em formato piramidal e amarrada com arames. Nessa técnica, coloca-se uma isca (alpiste/frutas/milho) para atrair e acostumar à ave a alimentar-se naquele local. Ao pousar, a arapuca cai sobre a presa, prendendo-a em seu interior.

O "quixó" (Figura 3L) é uma armadilha bastante simples e antiga, pouco utilizada para a captura de aves, sendo preferencialmente destinada à captura de pequenos mamíferos. Consiste em uma pedra grande suspensa por gravetos de madeira e é utilizada com algum tipo de alimento para atrair os animais. Qualquer movimento da presa desmonta o artifício de madeira e a pedra desaba sobre ela.

Outro método exclusivamente utilizado para a captura de aves é o "visgo", que consiste em um 
FIGURA 3: Fotografias de alguns instrumentos e técnicas de caça utilizadas na captura de aves silvestres pelos caçadores rurais do município de Jaçanã (Rio Grande do Norte, Brasil). (A, B, C) Arremedo; (D) Espingarda; (E) Fôjo; (F) Baladeira; (G) Assaprão; (H) Redinha; (I) Técnica - Caça com baladeira; (J) Arapuca; (L) Quixó; (M) Técnica - Caça com espingarda.


Fotos (A, B, C, D, F, G, H): Edja Daise. Foto (E): Graça Barbosa. Ilustrações (I, M): Kelvin Dantas; (J, L) Heberson Menezes. 
material bastante aderente, confeccionado pelos próprios caçadores através da mistura do leite de jaca (seiva de jaqueira) e da cinza do carvão. Nesta técnica, o material é colocado sobre galhos finos de árvores ou em poças d'água, de modo que, ao pousar, o pássaro fica colado. É comumente utilizado para a captura de exemplares vivos, sobretudo, Passeriformes. Registra-se o uso desse material em diferentes regiões do nordeste brasileiro (ROCHA et al., 2006; GAMA; SASSI, 2008; ALVES et al., 2009; FERNANDES-FERREIRA et al., 2010; 2012; BEZERRA et al., 2012b).

Foram citados, ainda que em menor frequência, armadilhas do tipo: "bozó", "fôjo" e "redinha", além da técnica "facheada" e a "técnica manual". O "bozó" consiste em uma gaiola de madeira ou macambira com dois ou mais compartimentos, cujas tampas são mantidas abertas em um sistema de desarme. Esta gaiola é utilizada para captura de aves de pequeno a médio porte, geralmente pássaros canoros, que serão destinados a comercialização ou para serem mantidos como animais de estimação. Para atrair as aves nesta técnica, os caçadores utilizam exclusivamente os "chamas".

O "fôjo" (Figura 3E) é uma armadilha desenvolvida sobre um buraco, cavado em um local estrategicamente escolhido pelo caçador, no qual se coloca uma lata de alumínio sobreposta com tábuas de madeira suspensas. Esse tipo de emboscada é pouco utilizado para a captura de aves, sendo geralmente destinada a captura de mamíferos de pequeno porte. Entretanto, relatos asseguram a captura de lambú (Crypturellus tataupa) por meio desta técnica.

A "redinha" (Figura 3H) é uma armadilha pequena semelhante a uma ratoeira (armadilha utilizada para a captura de ratos), constituída por madeira, arame e rede, formando um mecanismo de desarme que, eventualmente, será acionado sobre a presa atraída. No município de Jaçanã, os caçadores costumam colocar a "redinha" sobre ou dentro de uma "gaiola de campo", com dois ou mais compartimentos e, em alguns casos, também se utiliza como atrativo o "chama". Não foi encontrado registro do uso desta técnica na literatura pesquisada.

A "facheada" é uma técnica exclusivamente noturna, na qual os caçadores fazem o uso de algum utensílio luminoso na busca das aves, geralmente nos locais de nidificação. Já a "técnica manual” é realizada em qualquer horário. Quando realizada à noite, os caçadores costumam visitar os locais de nidificação das aves e as surpreendem com a luz da lanterna, não conseguindo voar por ficarem encandeadas com os fachos de luz, são coletadas facilmente. Quando praticada durante o dia, ocorre de forma semelhante, no entanto, nesse horário, ocorre principalmente a captura de filhotes diretamente nos ninhos. Ambas as técnicas foram registradas de forma semelhante por FernandesFerreira et al. (2010) no estado do Ceará.

Como forma de captura, foi mencionado também o uso de "arremedos" (Figura 3A, B, C), através de objetos de madeira ou plástico também conhecidos como "apitos", que emitem um som semelhante à vocalização do pássaro que se deseja capturar. Essa técnica costuma ser bastante utilizada no inverno, época que, segundo os indivíduos entrevistados, é o tempo de acasalamento. Adicionalmente, é interessante ressaltar que uma espécie pode ser capturada por diferentes técnicas, e em muitos casos, os caçadores fazem a junção de duas ou mais técnicas para obter sucesso nas caçadas. Similaridades no uso das técnicas aqui descritas foram relatadas por Alves et al. (2010b) no semiárido paraibano.

\section{Implicações conservacionistas}

É sabido que a caça e a perda de habitat constituem os maiores fatores de ameaça para a avifauna silvestre brasileira, de modo que, algumas espécies têm suas populações diminuídas drasticamente devido às ações antrópicas, acarretando diferentes distúrbios ambientais e, em alguns casos, extinções locais e/ou globais (SICK, 2001; MARINI; GARCIA, 2005; OLMOS, 2005; OLMOS et al., 2005). O declínio populacional da avifauna do município de Jaçanã foi percebido por (97\%) dos informantes. Os depoimentos evidenciam que algumas espécies, por terem sido bastante caçadas, têm suas ocorrências ameaçadas na região, como, por exemplo, a arribaçã (Z. auriculata), o canário-da-terra (S. flaveola - Figura $2 \mathrm{H}$ ) e as rolinhas (Columbina spp.). Vale salientar que, dentre as espécies listadas neste estudo, o táxon (Sporagra yarrellii) requer atenção especial por estar documentado na Lista da 
Fauna Brasileira Ameaçada de extinção (SILVEIRA; STRAUBE, 2008). Todavia, é necessário enfatizar que mesmo que determinado táxon não conste na lista das espécies ameaçadas nacionalmente, pode estar ameaçado regionalmente.

Nas áreas amostradas foi verificada a presença de diversas espécies de aves em cativeiro (para comercialização ou por estimação), configurando-se uma relação de domínio e/ou admiração. Aliado a isto, percebe-se que as espécies com reconhecido valor cinegético se referem à Passeriformes ou às utilizadas para fins alimentícios. É relevante ainda destacar que o caráter esportivo da caça na região estudada representa um forte fator de motivação da realização dessas atividades.

Foi observado que os caçadores utilizam diferentes técnicas para obterem sucesso nas caçadas, sustentando a ideia de que os mesmos possuem um apurado conhecimento sobre diferentes aspectos ecológicos desses animais. Adicionalmente, cabe inferir que algumas técnicas podem apresentar graus de impactos mais elevados, como a caça com espingarda, por se tratar de uma atividade que abate diversas espécies em um curto intervalo. Assim como a técnica manual, por ser um método seletivo que na maioria das vezes visa à captura de filhotes, ocasionando desequilíbrios populacionais, uma vez que o pássaro preso fica privado do processo reprodutivo (SICK, 2001).

Para mitigar estas ameaças várias ações conservacionistas podem ser efetivadas. No entanto, é preciso ressaltar, que a persistência da utilização da fauna silvestre no semiárido nordestino está diretamente associada a fatores econômicos e sócio-culturais, e que isto deve ser considerado para a definição de planos de ação para a conservação (OLMOS et al., 2005; ALVES et al., 2010b). Além disso, a falta de informação sobre o tamanho populacional e a distribuição das espécies são fatores que dificultam o estabelecimento de medidas conservacionistas (OLMOS et al., 2005).

A presente pesquisa amplia o conhecimento etnoornitológico no estado do Rio Grande do Norte, que por sinal é caracterizado por possuir poucas unidades de conservação (TORRES et al., 2009), além de ser uma das regiões brasileiras menos conhecidas do ponto de vista ornitológico e etnoornitológico, reforçando a necessidade da ampliação de estudos em torno das espécies exploradas, visando sistematizar informações e gerar dados que possam orientar ações conservacionistas em todo o estado.

Por fim, espera-se que este estudo forneça subsídios que possam ser utilizados como mecanismos de controle do uso da avifauna silvestre na região semiárida brasileira. Contudo, para que haja preservação ambiental é indispensável o apoio de órgãos responsáveis na criação de programas de conservação e gestão, incluindo: (1) Mapeamento das áreas e busca por novas populações de aves silvestres, sobretudo, por espécies endêmicas e ameaçadas de extinção. (2) Monitoramento do status populacional das espécies. (3) Manejo de ninhos. (4) Ampliação de áreas protegidas. (5) Campanhas educacionais. (6) Fiscalização por parte dos órgãos competentes. (7) Desenvolvimento de fontes alternativas de rendas sustentáveis para a população. Nesta perspectiva, o conhecimento tradicional local se converte em um componente decisivo para o esboço e implantação de estratégias conservacionistas.

\section{Agradecimentos}

Os autores agradecem à Prof ${ }^{a}$ Maria Franco Trindade Medeiros pela leitura crítica feita na primeira versão deste manuscrito; ao Prof. Oton Mário pela revisão gramatical; Heberson Menezes e Kelvin Dantas pelas ilustrações; Joakson Alves e Marcelo Dantas pelo apoio durante as atividades de campo e, de forma especial, aos informantes do município de Jaçanã que se dispuseram a conceder as entrevistas e permitir a realização da pesquisa.

\section{Referências}

ALBUQUERQUE, U. P.; LUCENA, R. F. P.; ALENCAR, N. L. Métodos e técnicas para coleta de dados etnobiológicos. In: ALBUQUERQUE, U. P.; LUCENA, R. F. P.; CUNHA, L. V. F. C. (Ed.). Métodos e técnicas na pesquisa etnobiológica e etnoecológica. Recife: Nupeea, 2010. p. 41-64.

ALMEIDA, S. M.; FRANCHIN, A. G.; MARÇAL-JUNIOR, O. Estudo etnoornitológico no distrito rural de Florestina, município de Araguari, região do Triângulo Mineiro, Minas Gerais. Sitientibus 
Série Ciências Biológicas, Feira de Santana, v. 6, n. especial, p. 26-36, 2006.

ALVARD, M. S.; ROBINSON, J. G.; REDFORD, K. H.; KAPLAN, $\mathrm{H}$. The sustainability of subsistence hunting in the neotropics. Conservation Biology, San Francisco, v. 11, n. 4, p. 977-982, 1997. ALVES, R. R. N.; GONÇALVES, M. B. R.; VIEIRA, W. L. S. Caça, uso e conservação de vertebrados no semiárido Brasileiro. Tropical Conservation Science, Menlo Park, v. 5, n. 3, p. 394-416, 2012.

ALVES, R. R. N.; LEITE, R. C. L.; SOUTO, W. M. S.; BEZERRA, D. M.; LOURES-RIBEIRO, A. Ethno-ornithology and conservation of wild birds in the semi-arid Caatinga of northeastern Brazil. Journal of Ethnobiology and Ethnomedicine, Londres, v. 9, n. 1, p. 9-14, 2013a.

ALVES, R. R. N.; LIMA, J. R. F.; ARAUJO, H. F. The live bird trade in Brazil and its conservation implications: an overview. Bird Conservation International, Cambridge, v. 23, n. 1, p. 53-65, 2013b.

ALVES, R. R. N.; MENDONCA, L. E. T.; CONFESSOR, M. V. A.; VIEIRA, W. L. S.; LOPEZ, L. C. S. Hunting strategies used in the semi-arid region of northeastern Brazil. Journal of Ethnobiology and Ethnomedicine, Londres, v. 5, n. 12, p. 1-16, 2009.

ALVES, R. R. N.; MENDONÇA, L. E. T.; CONFESSOR, M. V. A.; VIEIRA, W. L. S.; VIEIRA, K. S.; ALVES, F. N. Caça no semiárido paraibano: uma abordagem etnozoológica. In: ALVES, R. R. N.; SOUTO, W. M. S.; MOURÃO, J. S. (Ed.). A Etnozoologia no Brasil - Importância, status atual e perspectivas. Recife: Nupeea, 2010b. p. 347-378.

ALVES, R. R. N.; NOGUEIRA, E. E. G.; ARAUJO, H. F. P. Bird-keeping in the Caatinga, NE, Brazil. Human Ecology, Ithaca, v. 38, n. 1, p. 147-156, 2010a.

ALVES, R. R. N.; SOUTO, W. M. S. Etnozoologia: conceitos, considerações históricas e importância. In: ALVES, R. R. N.; SOUTO, W. M. S.; MOURÃO, J. S. (Ed.). A Etnozoologia no Brasil - Importância, status atual e perspectivas. Recife: Nupeea, 2010. p. $19-40$.

AMOROZO, M. C. M.; VIERTLER, R. B. A abordagem qualitativa na coleta e análise de dados em etnobiologia e etnoecologia. In: ALBUQUERQUE, U. P.; LUCENA, R. F. P.; CUNHA, L. V. F. C. (Ed.). Métodos e técnicas na pesquisa etnobiológica e etnoecológica. Recife: Nupeea, 2010. p. 66-82.

BAILEY, K. D. Methods of social research. 2. ed. New York: McMillan Publishers. The Free Press, 1982. 533 p.

BArbosa, J. A. A.; NOBREGA, V. A.; ALVES, R. R. N. Caça alimentar e de controle no agreste paraibano: técnicas, espécies exploradas e implicações conservacionistas. In: CONGRESSO DE ECOLOGIA DO BRASIL, IX, 2009, São Lourenço. Resumos... São Lourenço: CEB, 2009a. Versão eletrônica.

BARBOSA, J. A. A.; NOBREGA, V. A.; ALVES, R. R. N. Uso da fauna em uma comunidade tradicional no semi-árido paraibano: uma abordagem etnoecológica. In: CONGRESSO DE ECOLOGIA DO BRASIL, IX, 2009, São Lourenço. Resumos... São Lourenço: CEB, 2009b. Versão eletrônica.

BARBOSA, J. A. A.; NOBREGA, V. A.; ALVES, R. R. N. Aspectos da caça e comércio ilegal da avifauna silvestre por populações tradicionais do semiárido paraibano. Revista de Biologia e Ciências da Terra, João Pessoa, v. 10, n. 2, p. 39-49, 2010.
BEZERRA, D. M. M.; ARAUJO, H. F. P.; ALVES, R. R. N. Avifauna silvestre como recurso alimentar em áreas de semiárido no estado do Rio Grande do Norte, Brasil. Sitientibus Série Ciências Biológicas, Feira de Santana, v. 11, n. 2, p. 177-183, 2011 a.

BEZERRA, D. M. M.; ARAUJO, H. F. P.; ALVES, R. R. N. The use of wild birds by rural communities in the semi-arid region of Rio Grande do Norte State, Brazil. Bioremediation, Biodiversity and Bioavailability, v. 5, n. 1, p. 117-120, 2011 b.

BEZERRA, D. M. M.; ARAUJO, H. F. P.; ALVES, R. R. N. Aves silvestres como animais de estimação no semiárido do Rio Grande do norte, Nordeste do Brasil. In: SIMPÓSIO BRASILEIRO DE ETNOBIOLOGIA E ETNOECOLOGIA, IX, 2012, Florianópolis. Resumos... Florianópolis: SBEE, 2012a. Versão eletrônica.

BEZERRA, D. M. M.; ARAUJO, H. F. P.; ALVES, R. R. N. Captura de aves silvestres no semiárido brasileiro: técnicas cinegéticas e implicações para conservação. Tropical Conservation Science, Menlo Park, v. 5, n. 1, p. 50-66, 2012b.

BEZERRA, D. M. M.; ARAUjO, H. F. P.; ALVES, R. R. N. Avifauna de uma área de Caatinga na região Seridó, Rio Grande do Norte, Brasil. Ornithologia, Cabedelo, v. 6, n. 1, p. 53-69, 2013.

BIRDLIFE INTERNATIONAL. Threatened birds of the world. 2014. Disponível em: <http://www.birdlife.org/>. Acesso em: 7 mar. 2014.

CADIMA, C. I.; MARÇAL-JUNIOR, O. Notas sobre etnoornitologia na comunidade do distrito rural de Miraporanga, Uberlândia-MG. Bioscience Journal, Uberlândia, v. 20, n. 1, p.

81-91, 2004.

CARDOSO, S. H.; SABBATINI, R. M. E. Aprendendo quem é a sua mãe - $O$ comportamento do imprinting. Revista Cérebro \& Mente, 2001. Disponível em <http://www.cerebromente.org.br/ n14/experimento/lorenz/index-lorenzp.html $>$. Acesso em: 5 ago. 2013.

CBRO - COMITÊ BRASILEIRO DE REGISTROS ORNITOLÓGICOS. Listas das aves do Brasil. 2011. 10 ed. Disponível em <http://www.cbro.org.br>. Acesso em: 2 jun. 2013.

COLLAR, N. F.; WEGE, D. C.; LONG, A. J. Patterns and causes of endangerment in the New World avifauna. Ornithological Monographs, Califórnia, v. 48, p. 237-260, 1997.

DA SILVA, M.; FRAÇA, B. R. A.; IRUSTA, J. B.; SOUTO, G. H. B. O.; OLIVEIRA-JÚNIOR, T. M.; RODRIGUES M. C.; PICHORIM M. Aves de treze áreas de caatinga no Rio Grande do Norte, Brasil. Revista Brasileira de Ornitologia, São Leopoldo, v. 20, n. 3, p. 312-328, 2012.

FARIAS, G. B.; ALVES, Â. G. C. Aspectos históricos e conceituais da Etnoornitologia. Biotemas, Florianópolis, v. 20, n. 1, p. 91-100. 2007a.

FARIAS, G. B.; ALVES, A. G. C. Nomenclatura e classificação etnoornitológica em fragmentos de Mata Atlântica em Igarassu, Região Metropolitana do Recife, Pernambuco. Revista Brasileira de Ornitologia, São Leopoldo, v. 15, n. 3, p. 358-366, 2007 b.

FERNANDES-FERREIRA, H.; MENDONÇA, S. V.; ALBANO, C.; FERREIRA, S. F.; ALVES, R. R. N. Comércio e criação de aves silvestres (Psittaciformes, Piciformes e Passeriformes) no estado do Ceará. In: ALVES, R. R. N.; SOUTO, W. M. S.; MOURÃO, J. S. (Ed.). A Etnozoologia do Brasil - Importância, status atual e perspectivas. Recife: Nupeea, 2010. p. 381-402. 
FERNANDES-FERREIRA, H.; MENDONÇA, S. V.; ALBANO, C.; FERREIRA, F. S.; ALVES R. R. N. Hunting, use and conservation of birds in Northeast Brazil. Biodiversity and Conservation, New York, v. 21, n. 1, p. 221-244, 2012.

FERREIRA, C. M.; GLOCK, L. Diagnóstico preliminar sobre a avifauna traficada no Rio Grande do Sul, Brasil. Biociências, Porto Alegre, v. 12, n. 1, p. 21-30, 2004.

GAMA, T. F.; SASSI, R. Aspectos do comércio ilegal de pássaros silvestres na Cidade de João Pessoa, Paraíba, Brasil. Gaia Scientia, João Pessoa, v. 2, n. 2, p. 1-20, 2008.

GOGLIATH, M.; BISAGgIO, E. L.; RIBEIRO, L. B.; RESGALlA, A. E.; BORGES, R. C. Avifauna apreendida e entregue voluntariamente ao Centro de Triagem de Animais Silvestres (Cetas) do Ibama de Juiz de Fora, Minas Gerais. Atualidades Ornitológicas, On-line, Ivaiporã, v. 1, n. 154, p. 55-59, 2010.

HAYS, T. E. An empirical method for the identification of covert categories in Ethnobiology. American Ethnologist, Washington, v. 3, n. 3, p. 489-507, 1976.

IBGE - INSTITUTO BRASILEIRO DE GEOGRAIA E ESTATÍSTICA. 2010. Disponível em: <http://www.ibge.gov.br>. Acesso em: 2 fev. 2013.

IDEMA - INSTITUTO DE DESENVOLVIMENTO SUSTENTÁVEL E MEIO AMBIENTE DO RN. 2008. Disponível em: <http://www.idema.rn.gov.br>. Acesso em: 4 jun. 2013.

IUCN. Red list of threatened species. Version 2013.2. 2013. Disponível em: <http://www.iucnredlist.org>. Acesso em: 7 mar 2014.

LEAL, I. R.; SILVA, J. M. C. DA; TABARELLI, M.; LACHERJUNIOR, T. E. Mudando o curso da conservação da biodiversidade na Caatinga do Nordeste do Brasil. Megadiversidade, Belo Horizonte, v. 1, n. 1, p. 139-146, 2005.

LEE, R. J. Impact of subsistence hunting in North Sulawesi, Indonesia and conservation options. In: ROBINSON, J. G., BENNETT E. L. (Ed.). Hunting for sustainability in tropical forests. New York: Columbia University Press, 2000. p. 455-472.

LICARIÃO, M. R.; BEZERRA, D. M. M.; ALVES, R. R. N. Wild birds as pets in Campina Grande, Paraíba State, Brazil: An Ethnozoological Approach. Anais da Academia Brasileira de Ciências, São Paulo, v. 85, n. 1, p. 201-213, 2013.

MARINI, M. A.; GARCIA, F. I. Conservação de aves no Brasil. Megadiversidade, Belo Horizonte, v. 1, n. 1, p. 95-102, 2005.

MARIO, O. Jaçanã, meio século de história. Natal: Grafinorte, 2003. $121 \mathrm{p}$.

MEDEIROS, P. M.; ALMEIDA, A. L. S.; LUCENA, R. F. P.; SOUTO, F. J. B.; ALBUQUERQUE, U. P. Uso de estímulos visuais na pesquisa etnobiológica. In: ALBUQUERQUE, U. P.; LUCENA, R. F. P.; CUNHA, L. V. F. C. (Ed.). Métodos e técnicas na pesquisa etnobiológica e etnoecológica. Recife: Nupeea, 2010. p. 153-169.

MENDONÇA, L. E. T.; SOUTO, C. M.; ANDRELINO, L. L.; SOUTO, W. M. S.; VIEIRA, W. L. S.; ALVES, R. R. N. Conflitos entre pessoas e animais silvestres no semiárido paraibano e suas implicações para conservação. Sitientibus Série Ciências Biológicas, Feira de Santana, v. 11, n. 2, p. 185-199, 2012.
NOBREGA, V. A. Aspectos do uso e comercio de aves silvestres por populações tradicionais do agreste paraibano. In: CONGRESSO DE ECOLOGIA DO BRASIL, IX, 2009, São Lourenço. Resumos... São Lourenço: SBE, 2009. Versão eletrônica.

NOBREGA, V. A.; BARBOSA, J. A.; ALVES, R. R. N. Utilização de aves silvestres por moradores do município de Fagundes, semiárido paraibano: uma abordagem etnoornitológica. Sitientibus Série Ciências Biológicas, Feira de Santana, v. 11, n. 2, p. 165 175, 2011.

OLMOS, F. Aves ameaçadas, prioridades e políticas de conservação no Brasil. Natureza \& Conservação, Curitiba, v. 3, n. 1, p. 21-42, 2005.

Olmos, F.; SILVA, W. A. G.; ALBANO, C. G. Aves em oito áreas de caatinga no sul do Ceará e Oeste de Pernambuco, Nordeste do Brasil: composição, riqueza e similaridade. Papéis Avulsos de Zoologia, São Paulo, v. 45, n. 14, p. 179-199, 2005.

PAGANO, I. S. A.; SOUZA, A. E. B. A.; WAGNER, P. G. C.; RAMOS, R. T. C. Aves depositadas no Centro de Triagem de Animais Silvestres do IBAMA na Paraíba: Uma amostra do tráfico de aves silvestres no estado. Ornithologia, Cabedelo, v. 3, n. 2, p. 132-144, 2010.

PEREIRA, F. C.; BARACUHY, J. G. V. Contextualização do semiárido. In: ROCHA, A. P. T.; DE ABREU, B. S.; FURTADO, D. A.; BARACUHY, J. G. V.; NETO, S. F. (Ed.). Manejo ecológico integrado de bacias hidrográficas no semiárido brasileiro. 1 . ed. Campina Grande: CNPq, 2011. p. 9-37.

PEREIRA, G. A. 2010. Avifauna associado a três lagoas temporárias no estado do Rio Grande do Norte, Brasil. Atualidades Ornitológicas, On-line, Ivaiporã, v. 156, p. 53-60, 2010.

PEREIRA, G. A.; BRITO, M. T. Diversidade de aves silvestres brasileiras comercializadas nas feiras livres da Região Metropolitana do Recife, Pernambuco. Atualidades Ornitológicas, On-line, Ivaiporã, v. 126, p. 14-21, 2005.

PREUSS, J. F.; SCHAEDLER, P. F. Diagnóstico da fauna silvestre apreendida e resgatada pela polícia militar ambiental de São Miguel do Oeste, Santa Catarina, Brasil. Unoesc \& Ciência ACBS, Joaçaba, v. 2, n. 2, p. 141-150, 2012.

PHILLIPS, O. G., A. H.; REYNEL, C; WILKI, P.; GÁVEZDURAND, B. C. Quantitative Ethnobotany and Amazonian Conservation. Conservation Biology, San Francisco, v. 8, n. 1, p. 225-248, 1994.

REGUEIRA, R. F. S.; BERNARD, E. Wildlife sinks: quantifying the impact of illegal bird trade in street markets in Brazil. Biological Conservation, Boston, v. 149, n. 1, p. 16-22, 2012.

RENCTAS - REDE NACIONAL DE COMBATE AO TRÁFICO DE ANIMAIS SILVESTRES. 1ำ Relatório nacional sobre o tráfico de fauna silvestre. 2001. Disponível em: $<$ http://www. renctas.org.br/files/REL_RENCTAS_pt_final.pdf $>$. Acesso em: 5 ago. 2013.

RIBEIRO, L. B.; SILVA, M. G. O comércio ilegal põe em risco a diversidade das aves no Brasil. Ciência e Cultura, São Paulo, v. 59, n. 4, p. 4-5, 2007.

ROCHA, M. S. P.; CAVALCANTI, P. C. M.; SOUSA, R. L.; ALVES, R. R. N. Aspectos da comercialização ilegal de aves nas feiras livres de Campina Grande, Paraíba, Brasil. Revista de Biologia e Ciências da Terra, João Pessoa, v. 6, n. 2, p. 204-221, 2006. 
SAIKI, P. T. O. Conhecimento local sobre aves, com ênfase em Psittacidae, nos distritos rurais de Cruzeiro dos Peixotos, Martinésia e Tapuirama - Uberlândia - MG. 2008. 103 f.

Dissertação (Mestrado em Ecologia e Conservação de Recursos Naturais) - Universidade Federal de Uberlândia, Uberlândia. 2008.

SANTOS, I. B.; COSTA-NETO, E. M. Estudo etnoornitológico em uma região do semi-árido do estado da Bahia, Brasil. Sitientibus Série Ciências Biológicas, Feira de Santana, v. 7, n. 3, p. 273-288, 2007.

SICK, H. Ornitologia brasileira. Rio de Janeiro: Nova Fronteira, 2001. $862 \mathrm{p}$

SILVA, J. M. C.; SOUZA, M. A.; BIEBER, A. G. D.; CARLOS, C. J. Aves da caatinga: status, uso do habitat e sensitividade. In: LEAL, I. R.; TABARELLI, M.; SILVA, J. M. C. (Ed.). Ecologia e Conservação da Caatinga. Recife: Ed. Universitária da UFPE. 2003. p. 237-273.

SILVEIRA L. F.; MÉNDEZ, A. C. Caracterização das formas brasileiras do gênero Sicalis (Passeriformes, Emberizidae). Atualidades Ornitológicas, On-line, Ivaiporã, n. 90. p. 6-8, 1999.
SILVEIRA, L. F.; STRAUBE, F. C. Aves ameaçadas de extinção no Brasil. In: MACHADO, A. B. M.; DRUMOND, G. M.; PAGLIA, A. P. (Ed.). Livro vermelho da fauna brasileira ameaçada de extinção. Vol. 1. Brasília: ICMBio, 2008. p. 378-669.

SOUZA, G. M.; SOARES-FILHO, A. O. Comércio ilegal de aves silvestres na região do Paraguaçu e Sudoeste da Bahia. Enciclopédia Biosfera, Goiânia, v. 1, n. 10, p. 1-11, 2005.

SPRADLEY, J. P.; MCCURDY, D. W. The cultural experience: ethnography in complex society. Tennessee: Kingsport Press of Kingsport, 1972. 246 p.

TORRES, D. F.; OLIVEIRA, E. S.; ALVES, R. R. N.; VASCONCELLOS, A. Etnobotânica e Etnozoologia em unidades de conservação: Uso da Biodiversidade na Apa de Genipabu, Rio Grande do Norte, Brasil. Interciencia, Caracas, v. 34, n. 9, p. 623629, 2009.

VARELA-FREIRE, A. A.; ARAÚJO, S. A. Zoogeografia do Rio Grande do Norte. In: A Ornitofauna do Seridó Potiguar. Caderno Norte-Rio-Grandense de Temas Geográficos, Natal, n. 11, p. 52$81,1997$. 